\title{
Article \\ The New Education Policy 2020, Digitalization and Quality of Life in India: Some Reflections
}

\author{
Kunnummal Muralidharan ${ }^{1}$ (D), Kulandaivel Shanmugan ${ }^{2}$ and Yury Klochkov ${ }^{3, * \mathbb{D}}$ \\ 1 Department of Statistics, Faculty of Science, Maharajah Sayajirao University of Baroda, \\ Vadodara 390 002, India; muralikustat@gmail.com \\ 2 Department of Business Economics, Faculty of Commerce, Maharajah Sayajirao University of Baroda, \\ Vadodara 390 002, India; shanmuganmsu@gmail.com \\ 3 Department of Quality Assurance Engineering, Peter the Great St. Petersburg Polytechnic University, \\ St. Petersburg 195251, Russia \\ * Correspondence: y.kloch@gmail.com
}

check for updates

Citation: Muralidharan, K. Shanmugan, K.; Klochkov, Y. The New Education Policy 2020,

Digitalization and Quality of Life in India: Some Reflections. Educ. Sci. 2022, 12, 75. https://doi.org/ 10.3390 /educsci12020075

Academic Editor: James Albright

Received: 30 November 2021

Accepted: 13 January 2022

Published: 21 January 2022

Publisher's Note: MDPI stays neutral with regard to jurisdictional claims in published maps and institutional affiliations.

Copyright: (C) 2022 by the authors. Licensee MDPI, Basel, Switzerland. This article is an open access article distributed under the terms and conditions of the Creative Commons Attribution (CC BY) license (https:// creativecommons.org/licenses/by/ $4.0 /)$.

\begin{abstract}
The democratic welfare government is not only interested in creating educational institutions as infrastructure for education for all, but is also equally keen on quality-oriented, even-handed, and equitable education. In fact, the focus of the Global Agenda SDG 4 is to raise the standard of living and quality of life by ensuring quality and lifelong education irrespective of region, race, religion, color, and caste, etc. Thus, there is a strong focus in India to reach global targets and more importantly, this is due to the necessity of fulfilling the government's goals on overhauling India's education system in the context of far-reaching changes that have taken place in terms of economic, social, and scientific areas over a period of last twenty years. The outcome of all these complex issues and critical thinking across stakeholders in social development manifested into policy action called the New Education Policy 2020 (NEP 2020). Therefore, it is critically important to analyze the subject under study as a compact system composed of simultaneous relationships to give a combined effect of the objectives and the framework undertaken for the analysis. Quality of life and education are the variables that are difficult to precisely measure in quantitative terms and hence, the implications and inferences are carefully analyzed on the range of issues that are selected for statistical analysis and structural modeling. By going with our estimates, it seems that though NEP 2020 is a popular and mandated educational policy for educational reforms and for a better future, the expected implementation of the policy would be very difficult in the context of digitalization and for raising the quality of life. In our opinion, remarkable progress on the quality of life can be made possible with flexibility in proper life-long education and training, which can culminate skill, experience, quality of education, and rigidity of the segmented labor market into better opportunities and employment.
\end{abstract}

Keywords: national education policy; sustainable development; digitalization; quality of life; structural modeling; inclusive education

\section{Introduction}

Social development and egalitarian democratic processes are mutually influenced by the appropriate and dynamic changes in the educational system that people want to adopt over a period depending upon how adoptive cultural expectations grow. Changes and paradigm shifts in the knowledge gaining process and policies that govern the same are invariability dictated alongside the representative democratic will and solidarity of economic growth and development. Probably the meaningful and sustainable economic development is the precondition for the evolution of a good educational system, and multidimensional facets of developing a fair and equitable educational process also require a strong economic base and considerable expenditure both by the public and private sectors. Education by itself is a qualitative phenomenon that has an enormous capacity to impact 
social, cultural, political, economic, and scientific aspects of human life. The consensus in economic science would suggest that education is a meritorious mixed commodity in which there is a spillover effect for society from individuals who have attained some level of education on various parameters of social development. It is a mixed commodity in the sense that education possesses the characteristics of both private and public good and, therefore, there are challenges in the creation and dissemination of knowledge.

Individuals do not necessarily acquire knowledge from the formal educational system and traditional methods; informal training and experiences have been given considerable awareness and realization to promote individual and social welfare. Humans have learned hard lessons to gain the knowledge necessary for both survival and development. Hence, it is imperative to understand that knowledge has not originated from the formal educational system. The formal educational system has conducted inquiry and investigation more scientifically to gain a very deeper understanding of the area and subjects of the social interests. This has culminated into a very large body of literature over a period on a crosssection of the subjects and today formal educational system stands as indispensable social order and norm. The growth of educational institutions has multiplied many folds across the world in providing primary, secondary, and higher educations.

The democratic welfare government is not only interested in creating educational institutions as infrastructure for educating all but is also equally keen on quality-oriented, even-handed, and equitable education. India is not an exception to this rule, and, at the same time, educational realities are uniquely different from what is conceived in India as political, social, cultural, and economic constraints have played major roles in exclusion and alienation. The government's educational policies have been addressing these realities comprehensively and unequivocally to have inclusive education and reduced educational inequalities. The government of India, along with state governments, has evolved numerous policy measures and programs for building a strong educational system and most of the policies have addressed the issues of accessibility and equity. To mention a few, the policies of 1968, 1986, and 1992 have extensively dealt with equity and justice in promoting education to all. Creating a vibrant educational system that can deliver the social objectives across time and space is basically directed by the economic considerations, opportunities, the educational delivery mechanism, very well-trained educators, educational aids, technology, digitalization, etc. (For more elaborative discussion, one can refer to government policy documents particularly that of 1986 and 1992. Also, the annual report of the ministry of education, Government of India).

Sustainable Development Goal IV (SDG 4) of the United Nations clearly emphasizes that the main aim of the educational system should be that of serving "Quality Education" and it has given a full understanding of the specific actions to be taken by all the nations by 2030 to "Ensure inclusive and equitable quality education and promote lifelong learning opportunities for all". In fact, the focus of the Global Agenda SDG 4 is to raise the standard of living and quality of life via ensuring quality and lifelong education irrespective of region, race, religion, color, caste, etc. Thus, there is a strong focus in India to reach global targets and more importantly, this is due to the necessity of fulfilling the government's goals on overhauling India's education system in the context of far-reaching changes that have taken place in terms of economic, social, and scientific areas over a period of last twenty years. The clear outcome of these complex issues and critical thinking across stakeholders of social development manifested into a policy called the New Education Policy 2020 (NEP 2020, [1]). According to the NEP 2020, "The purpose of the education system is to develop a good human being capable of rational thought and action, possessing compassion and empathy, courage and resilience, scientific temper, and creative imagination, with sound ethical mooring and value. It aims at producing engaged, productive, and contributing citizens for building an equitable, inclusive, plural society as envisaged by our Constitution". This articulates the essence of various ingredients which are desired for the quality of life of individuals and social development. 
The policy document of NEP 2020 and its implementation since last year has been placing emphasis on certain fundamental principles, such as recognizing, identifying, and fostering the unique capabilities of each student; flexibility in learning; creativity and critical thinking: and so on, that will guide the future of education system and institutions in developing knowledge, skills, values, and dispositions to support quality of life, sustainable development, and global well-being. There is a fundamental change in the pedagogical and curricular structure from the early childhood education up to higher education not only to attain 100\% Gross Enrolment Ratio (GER) but also to effectively prevent dropout rates by providing opportunities and infrastructure to attend a quality school including carefully tracking the students so as to give fundamental and sufficient educational investment for human development and quality of life. A critical and important dimension of this policy at all levels of education is digitalization and this process of digitalization gets boosted in the system with the introduction of lifelong learning and flexibility. More increasingly the digitalization is going to occupy the process of enrolments, designing of curriculum, pedagogy, and evaluation, and subsequently, it will transform the educational development and knowledge gaining process of individuals who are in the formal system of education. This is very important for the quality of life of individuals in the contexts of social, cultural, and economic elements of human life of the future India. Our attention is not on NEP 2020 but rather analytically and empirically examining the implications of various key policy initiatives of NEP 2020 on quality of life while keeping digitalization of education and other aspects of the same on human life as focal points.

The per capita net national income during 2020-2021 is \$1927.7 compared to the per capita income $\$ 1605.6$ in 2015. It is also important to note that at the beginning of COVID19 pandemic, India enjoyed the highest per capita income of \$2100 during 2019 and it is evident that there is a drop in the per capita income due to a sharp decrease in the GDP growth rate. This has resulted in the implementation of programs pertaining to information and communication-enabled processes of educational development and growth. It is also important to note the literacy rates, which is a fair indicator of educational spread and gives a clear understanding of the population under consideration for the overall benefit of the new educational policy in India, stood $77.7 \%$ overall during 2021 as compared to 71.9 in 2015, which is around a 5.8\% increase in the literacy rates. If one looks at male-female classifications of literacy rates, there are considerable improvements as $84.7 \%$ and $70.3 \%$, respectively, for males and females during 2021 as against $80.9 \%$ and $62.9 \%$ in 2015 . The rise in the literacy rates, which is due to an enormous boost given by various federal government policies including that of support from the private sector, indicate a structural transformation of educational development and the adoptability of institutional framework in fostering the digital and online educational modes.

According to Trading Economics, "the employment rate in India averaged $44.97 \%$ from 2012 until 2020, reaching an all-time high of 50.80\% in the fourth quarter of 2012 and a record low of $36.4 \%$ in the second quarter of 2020 ". The noticeable fall in the employment rate has been observed as a result of economic recession and, more recently, due to a significant negative impact of COVID-19. All these estimates put together reveal that the ability of the population to adopt digitalization in order to reap the benefits of new education policy has been considerably constrained with fewer opportunities for income earning as employment has been falling coupled with a decline in the per capita income. The declining GDP and adverse effect of the current pandemic might force a significant fall of QOL in the short run and probably might get restored in the long run, and this will play a crucial role in adopting the various essences of NEP 2020.

The article is organized in the following way: While Section 1 deals with the introduction and background required for analysis, the literature review is examined in Section 2. The methodology is presented in Section 3. The details about the population, sample, questionnaire, and data structures and objectives of the analysis are presented in this section. The Data Analysis and findings are developed in Section 4. The compact structural modeling and its estimations, including the analytical perspectives, are studied 
in Section 5. This study presents its limitation in Section 6 and while conclusions and policy recommendations are placed in the last section.

\section{Literature Review}

There is hardly any methodological research carried out by researchers on NEP 2020 so far. However, the events by the government to provide awareness and educate the stakeholders are widespread, to some extent. We strongly believe that NEP 2020 as a policy document is advocating holistic education in its true nature and spirit, involving every stakeholder under a uniform platform. It is observed that the vastness of the document and various dimensions of the policy reflect the greater emphasis on quality of life. The policy also articulates equitable and inclusive education touching quality of life to a wider extent while meeting its intended objectives. The concept of Quality of Life (QOL) was evolved and popularized by the world bodies like UNDP, WHO, and the World Bank in measuring improvement in the status of the living condition of people belonging to developing countries as against those of the developed countries. However, it has been found that the prescribed human development indices are not adequate to meaningfully appraise the QOL. The Human Development index introduced by UNHDP [2] is based on the well-being of people, which includes education as an indicator. Ascertaining QOL involves some assessment of welfare, whether of the individual or of the collective, and this assessment typically involves objective (i.e., measurable in terms of quantity or frequency) and subjective (i.e., measurement contingent on the perception of the individual) indicators [3-5]. According to [3], one of the characteristic difficulties in QOL research is that subjective and objective indicators are often poorly correlated, and so it is a common practice to include both components in research. Subjective measures typically involve self-report surveys or interviews, and objective measures include per capita income, life expectancy, morbidity rates, literacy rates, average or median level of educational attainment, and unemployment rates $[4,6]$. Some studies $[7,8]$ conclude that various institutional features of education systems determine their "capacity to structure" students' transition into the workforce. Others $[9,10]$ consider the social indicators equivalent to educational indicators as the markers of the distribution of living conditions within society. As per their findings, social indicators are statistical tools useful to policymakers for monitoring various aspects of social systems and for guiding the implementation and evaluation of policies directed at improving and maintaining QOL.

Lonescu et al. [11] explore the relationship between investments in education and research and the level of quality of life in a country through various composite indicators and establish positive relation between investments in education and QOL. The investments in education and research are expressed in terms of expenditure on education and research, financial aid and public subsidies to the private sector, and so on. According to the compendium of [12], education and skills have a strong influence on people's well-being. Better educated individuals earn higher wages and have a higher probability of having a job, and they also participate more actively in politics and in the community where they live. At the level of society, a better education leads to higher GDP growth, higher tax revenues, and lower social expenditures. A study carried out by [13] concerning Kenya argues that free basic education at the primary level and secondary school enrolment and completion are more likely to improve QOL. A related study by [14] considers the effects of the local human capital level and the presence of higher education institutions on the QOL in U.S. metropolitan areas. The author establishes the fact that the QOL is positively affected by both the local human capital level and the relative importance of higher education institutions.

A current study based on technical-technological data related to higher education [15] proposes various optimal management strategies for quality improvement in higher education institutes (HEI's). The authors believe that the proposed system based on quantitative data and genetic algorithm can enable the simulation and verification of different scenarios for improving the quality and performance of the system, which can yield positive effects 
on the management and improvement of the given HEIs. Another study [16] analyzes the correlation to identify interrelations between digitalization and QOL, and the potential of using the visualization matrix method to identify and monitor national trends of digitalization in the context of QOL. In a study by [17], the authors investigate the association between digital inclusion and QOL and address endogeneity with simultaneous equation models and instrumental variable methods. They believe that the existing single equation-based empirical model can provide specific insights to several variables and then establish the association between digital inclusion and QOL. According to [18], for being practical, the government should be an early adopter of new technology rather than solely relying on industry to lead the way. Through technological leadership, the government can play an important role in spurring markets and proving concepts for sustaining advancements in quality life. Correa [19] argues that the new online applications and tools have emerged with the potential to transform education by improving learning outcomes, serving multiple learning styles, and expanding access to education.

The importance of digital online education has peaked since the outbreak of COVID-19 across the world. It has changed every facet of educational activities, putting human intelligence and machines into play. Although it was a necessity due to social distancing, people have adopted and accepted digital technology as they are the only option available to them. The experimentation is paving the way for the new addition of newer technologies and curriculum development to the need of the people. Innovation is a crucial force underlying the organizational and societal ability to survive and thrive in a crisis, especially in education [20]. Through their research study, [21] determines the possibilities and effects of mobile application as support in foreign language learning (professional language) on bachelor studies as a part of engineering and technical and technological sciences curricula (see also [22]). The ever-existing tension between the costs and benefits of organizational innovation [23] is accentuated in times of severe crisis, such as the COVID-19 pandemic. Many organizations and educational institutions struggle to maintain their operation in the turbulent environments caused by the pandemic, which forces them to be extremely cost-effective [24] and consequently cut budgets for innovation.

According to the Education for Sustainable Development (ESD) sourcebook published in 2012 by UNESCO, reorienting a curriculum to address sustainability can take place at the classroom or national level. At the classroom level, teachers can begin by explicitly asserting the link between the topics in the mandated syllabus and on sustainability. A national or state-level process would include inviting stakeholders to a public participation process to gather input (e.g., statements of needs and desires as well as opinions) related to the reorienting process. To reorient a curriculum to address sustainability, educational communities need to identify the knowledge, issues, perspectives, skills, and values central to sustainable development in each of the three components of sustainability-environment, society, and economy-and integrate them into the curriculum $[25,26]$.

A recent study by Muralidharan [27] articulates the principles of Lean, Green, and Clean concepts in developing a sustainable quality of life. Lean is a practical methodology for improving the speed and execution of a process, along with the identification of wastes. According to the Lean philosophy, wastes are non-value-added activities of a process and should not be allowed to recur [28-30]. However, the green concepts promote sustainable practices, which generally mark the growth and prosperity of people and processes. A Lean environment that generates green practices automatically guarantees a clean framework. A Clean quality of life promotes the well-being of the person and society to prosper. Thus, the Lean, Green, and Clean concepts are a rewarding experience for all to improve their quality of life. Although not directly connected with the QOL [31], studies the comparative assessment of sustainable consumption based on the digital information environment content using computer linguistic tools. An innovative study by [32] examines a multidisciplinary aspect of sustainable development goals and the theme is dealt with by a cross-section of areas ranging from economics, applied statistics, and other social sciences to provide a meaningful and holistic approach to the subject chosen. 
Without connecting education on QOL directly, [33] describes QOL Therapy and Coaching as a tool for evidence-based well-being, happiness, and positive psychology suitable for developing QOL Therapy and Coaching are delineated in the context of an illustrative case and an underlying theory which attempts to integrate findings from the fields of well-being, positive psychology, happiness, quality of life, social indicators, psychotherapy, and coaching. Based on secondary data, [34] examine that various levels of higher education are associated with a wide range of positive outcomes-including better health and well-being, higher social trust, greater political interest, lower political cynicism, and less hostile attitudes towards immigrants. The study also points out that people who reported that they were satisfied with their education and subsequently incorporated education as part of their identity have been benefitted psychologically. Mahajan et al. [35] discuss various reflections from stakeholders of higher education in India and this e-book contains the opinions of 106 stakeholders coming from a variety of professions and their perceptions on numerous aspects of education in reference to the new education policy. We expect that our attempt brings forth some important analytical perspectives which can provide a reference tool for linking QOL, digitalization, and NEP 2020 while giving some policy recommendations for the desired outcome of NEP 2020 in the future.

\section{Methodology}

\subsection{Objectives}

This exercise essentially deals with QOL as a target variable while exploring the possibilities of digitalization of the educational system conceived in NEP 2020 through the angles of both school and higher educations. This survey treated the opinions and the responses in terms of observations and expectations on the variables that we have included in this study. The information is drawn to provide systematic structural mechanisms while taking into consideration some of the key aspects of NEP 2020 for analyzing the implications on social well-being, social development, and QOL. Those structural mechanisms can be organized as a set of key objectives; simultaneously, they can be treated as hypotheses in the following manner:

1. Experimental learning, new pedagogical curriculum structure, and flexibility in learning may give scopes for improvement in the overall standard and quality of education.

2. Integration of knowledge, skill development, and employability through holistic education are likely to provide better opportunities.

3. The multidimensional development conceived on physical, mental, and emotional areas of human beings will elevate QOL.

4. The key agenda of government on digitalization of education in its all aspects presumably can produce synergies required for human and social development.

5. A multidisciplinary approach, lifelong learning, and fostering the unique capabilities of learners invariably will strengthen QOL.

\subsection{Frame of Study and Data Issues}

The study is conducted through a two-phase data collection procedure. The first phase is based on the population of all types of stakeholders and is limited to people of Indian nationals only. The data is collected through an online Google form distributed via emails, social networks, and contact groups. The reason for doing such an exercise was to know to what extent people are aware of this NEP 2020. To make it more meaningful, we also included all age groups, including students, whose minimum age considered was 20 years, to understand the level of awareness among a cross-section of age groups. Our target population was those who have clear internet connectivity and have some idea about NEP 2020. Given this population, we randomly selected 750 units of inquiry as a sample and finally, we received 523 responses.

The sample size is an important consideration for the cross-section survey carried out in our analysis, and the authors are fully aware of the limitations in obtaining G-responses and randomizing them. The population chosen here is highly restricted and does not 
consider all existing individuals in the country. Even for asymptotic properties, the choice made here is suited to both distributional characteristics and structural estimation. Since the NEP 2020 was introduced during the last quarter of 2020 only, the policy recommendations were not fully percolated to stakeholders like students and parents. However, the teachers and government stakeholders across the nation were introduced through nation-wise seminars and contact programs on online digital platforms to some extent, which is still going on. As suggested by the reviewer, it makes sense to have a study based on a large population, and that may be attempted in the future. This we considered as responses from phase 1 . We found that $98 \%$ of the respondents reasonably understood various features of NEP 2020, and the remaining $2 \%$ of cases did not have any information on the same. Owning to the fact that we have not included anybody below the age of 20 years accordingly, information from these respondents was also excluded. We have also undertaken a random selection of 50 respondents (believed to be the direct stakeholders) for direct interaction with the questionnaire during the second phase, and their opinions were included for the analysis. After going through the first and second phases, finally, we arrived at 493 cases of respondents who provided complete information and opinions that were asked through a questionnaire. The collected information was put into randomization by stratified random sampling, and further information was systematically coded, classified, and organized for statistical data analysis and model building.

\subsection{Questionnaire}

The questionnaire is classified into five important sub-categories, in which the first category pertains to personal information about the respondent, including that of respondent's awareness regarding NEP 2020. The second section of the questionnaire goes into the details of information on school education and various aspects of NEP 2020. While Category 3 tries to extract key information on higher education and its complex diversities, Section 4 brings a cross-section of data on digitalization, which includes online program, educational videos, animations, picture content, cost of digitalization, etc. The last section deals with the collection of data on QOL. The details of NEP 2020 along with specific questions with their codes, are provided in Appendix A. The prepared questions are rated on a five-point scale as shown in the tabels Appendix A. There are no open-ended questions. This survey includes about 56\% teachers and academic stakeholders and $33 \%$ of students at higher education institutes (HEI). The remaining respondents are from other backgrounds (freelancers, NGOs, government, and private employees). Out of all respondents, 49\% are from age groups between 20 to 40 , and $42 \%$ are from the age group of 40 to 60 . The remaining are above 60 . For the sake of brevity, statistical analysis and structural modeling, all the responses from the questions are summarized question-wise into variables, which are listed in column 2 of Table 1.

\subsection{Model Building}

It is critically important to analyze the subject under study as a compact system composed of simultaneous relationships to give a combined effect of the objectives and the framework undertaken for the analysis. Keeping this broad notion in mind, a structurally compatible simultaneous equation model was developed to give interplay of variables that have been selected to understand the QOL. To do the same, we have renamed the variables in column number 2 of Table 1 into the names suitable for the structural modeling. The details about the same are mentioned in Section 7. Depending upon the directions of the responses, changes in the endogenous and explanatory variables must be interpreted in the scaling format. 
Table 1. Directions of values expressed in terms of percentages for the concerned variables from the questionnaire.

\begin{tabular}{|c|c|c|c|c|c|}
\hline \multirow{2}{*}{ Serial No. } & \multirow{2}{*}{ Variables } & \multicolumn{2}{|c|}{ Optimistic Scenario } & \multicolumn{2}{|c|}{ Pessimistic Scenario } \\
\hline & & Disagreement & Agreement & Disagreement & Agreement \\
\hline 1 & QV_1 & 9.32 & 90.68 & 31.36 & 68.64 \\
\hline 2 & QV_2 & 4.24 & 95.76 & 15.25 & 84.75 \\
\hline 3 & QV_3 & 11.02 & 88.98 & 22.88 & 77.12 \\
\hline 4 & QV_4 & 11.86 & 88.14 & 21.19 & 78.81 \\
\hline 5 & QV_5 & 10.17 & 89.83 & 35.59 & 64.41 \\
\hline 6 & QV_6 & 17.80 & 82.20 & 28.81 & 71.19 \\
\hline 7 & QV_7 & 7.63 & 92.37 & 19.49 & 80.51 \\
\hline 8 & QV_8 & 5.93 & 94.07 & 27.97 & 72.03 \\
\hline 9 & QVI_1 & 16.10 & 83.90 & 46.61 & 53.39 \\
\hline 10 & QVI_2 & 30.51 & 69.49 & 56.78 & 43.22 \\
\hline 11 & QVI_3 & 8.47 & 91.53 & 33.05 & 66.95 \\
\hline 12 & QVI_4 & 20.34 & 79.66 & 45.76 & 54.24 \\
\hline 13 & QVII_1 & 11.02 & 88.98 & 22.03 & 77.97 \\
\hline 14 & QVII_2 & 6.78 & 93.22 & 18.64 & 81.36 \\
\hline 15 & QVII_3 & 6.78 & 93.22 & 17.80 & 82.20 \\
\hline 16 & QVII_4 & 20.34 & 79.66 & 49.15 & 50.85 \\
\hline 17 & QVII_5 & 29.66 & 70.34 & 50.00 & 50.00 \\
\hline 18 & QVII_6 & 21.19 & 78.81 & 44.92 & 55.08 \\
\hline 19 & QVII_7 & 18.64 & 81.36 & 47.46 & 52.54 \\
\hline 20 & QVII_8 & 14.41 & 85.59 & 38.14 & 61.86 \\
\hline 21 & QVII_9 & 38.98 & 61.02 & 58.47 & 41.53 \\
\hline 22 & QVII_10 & 16.10 & 83.90 & 41.53 & 58.47 \\
\hline 23 & QVII_11 & 9.32 & 90.68 & 32.20 & 67.80 \\
\hline 24 & QVIII_1 & 26.27 & 73.73 & 51.69 & 48.31 \\
\hline 25 & QVIII_2 & 33.05 & 66.95 & 50.00 & 50.00 \\
\hline 26 & QVIII_3 & 22.03 & 77.97 & 34.75 & 65.25 \\
\hline 27 & QVIII_4 & 8.47 & 91.53 & 23.73 & 76.27 \\
\hline 28 & QVIII_5 & 11.02 & 88.98 & 26.27 & 73.73 \\
\hline 29 & QVIII_6 & 13.56 & 86.44 & 25.42 & 74.58 \\
\hline 30 & QVIII_7 & 16.95 & 83.05 & 35.59 & 64.41 \\
\hline 31 & QVIII_8 & 18.64 & 81.36 & 36.44 & 63.56 \\
\hline 32 & QVIII_9 & 10.17 & 89.83 & 20.34 & 79.66 \\
\hline 33 & QVIII_10 & 24.58 & 75.42 & 55.08 & 44.92 \\
\hline
\end{tabular}

(Source: Author's calculation from the questionnaire survey). 


\section{Data Analysis and Findings}

The normative wisdom propels to analyze the data obtained from the questionnaire survey into various angles, to give, the foundation for critical analysis and simultaneous equation model building. Accordingly, this section elucidates various dimensions of information collected. Preliminary understandings of the questionnaire, which are formed in terms of scaling, are converted into variables to give an appropriate expression for basic data analysis and structural modeling. This is summarized in Table 1.

This study arranges the responses into two broad categories, namely, optimistic scenario and pessimistic scenario. An optimistic scenario is conceived as people with neutral responses evaluate NEP 2020 as a chance and opportunity for social merit and for strengthening QOL. Behavioral economic analysis in particular and social science, in general, perceive educational development as a process for both consumption and investment. These two activities create and disseminate utilities for social welfare. If people happen to perceive this idea, the logical responses will be optimistic and therefore, the respondent will move from neutral to an agreement. The information on the optimistic scenario is presented in columns 3 and 4 of Table 1 . A pessimistic scenario clubs the responses of neutrality into a disagreement. The theoretical and analytical reason for doing this is that the government policies, in particular NEP 2020, might get negative feedbacks in the society as complicated socio-cultural factors and the development in the institutional and political-economic compulsions of implementing NEP 2020 could push the negative sentiments. To give this scope, we have organized the responses in columns number 5 and 6 of Table 1 . The critical reason for neutral responses turning into disagreements can be clearly explained by social rigidities, inequalities in terms of social, educational, and economic domains. This can further be pushed by large political engagement against governmental policies.

As evident from Table 1 of column 4 , in an optimistic scenario, most of the respondents have revealed their preferences in favor of policy initiatives and the futuristic implementation plan of NEP 2020. Therefore, a unidimensional opinion can be observed overwhelmingly in terms of the percentages as indicated in the table. There are some disagreements even in the optimistic scenario on certain key variables, which can be noticed in column 3 of Table 1. As far as the pessimistic scenario is concerned, the responses are mixed into agreement and disagreement. In fact, some of the variables cross more than $40 \%$, which is a sign of considerable disagreement in the democratic process of implementing educational goals. However, higher percentages are evident in the agreement even in the pessimistic scenario, and both pessimistic and optimistic scenarios can be treated as extreme cases. The real scenario of outcomes of NEP 2020 probably would lie somewhere in between these two extremes. How closely the real scenario falls on either extreme depends critically on political, social, cultural, and economic dynamics that would emerge in time to come.

As expected, there is no significant association between the profession and age group. To understand the relative importance of people's agreement (agree + strongly agree) with disagreement (disagree + strongly disagree), we carried out a two-sample MannWhitney test on the combined score. The test is found to be highly significant in all five components. This significance establishes the fact that the respondents have common perceptions towards education on QOL. This is evident from Figures 1 and 2, where Figure 1 shows the distribution of responses combined on each question of the first four components, and Figure 2 is the distributions of responses that correspond to the QOL component. From Figure 2, it is observed that there are about $50 \%$ of respondents, who believe that the NEP 2020 can enhance QOL and roughly $38 \%$ of respondents opine that the new policy can improve QOL moderately. Thus, according to the combined figure, $88 \%$ of respondents' views may be evaluated as a basis for future changes and amendments while incorporating QOL components in the policy framework. 


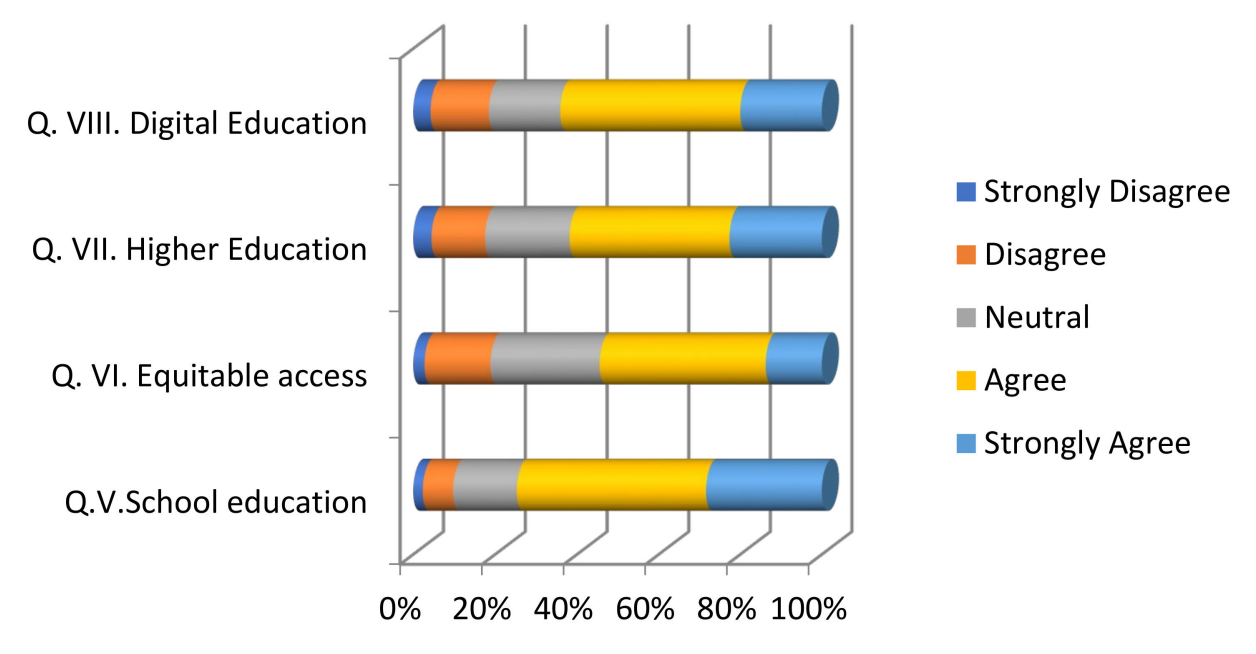

Figure 1. Distribution of responses in component-wise. (Source: Author's calculation from the questionnaire survey).

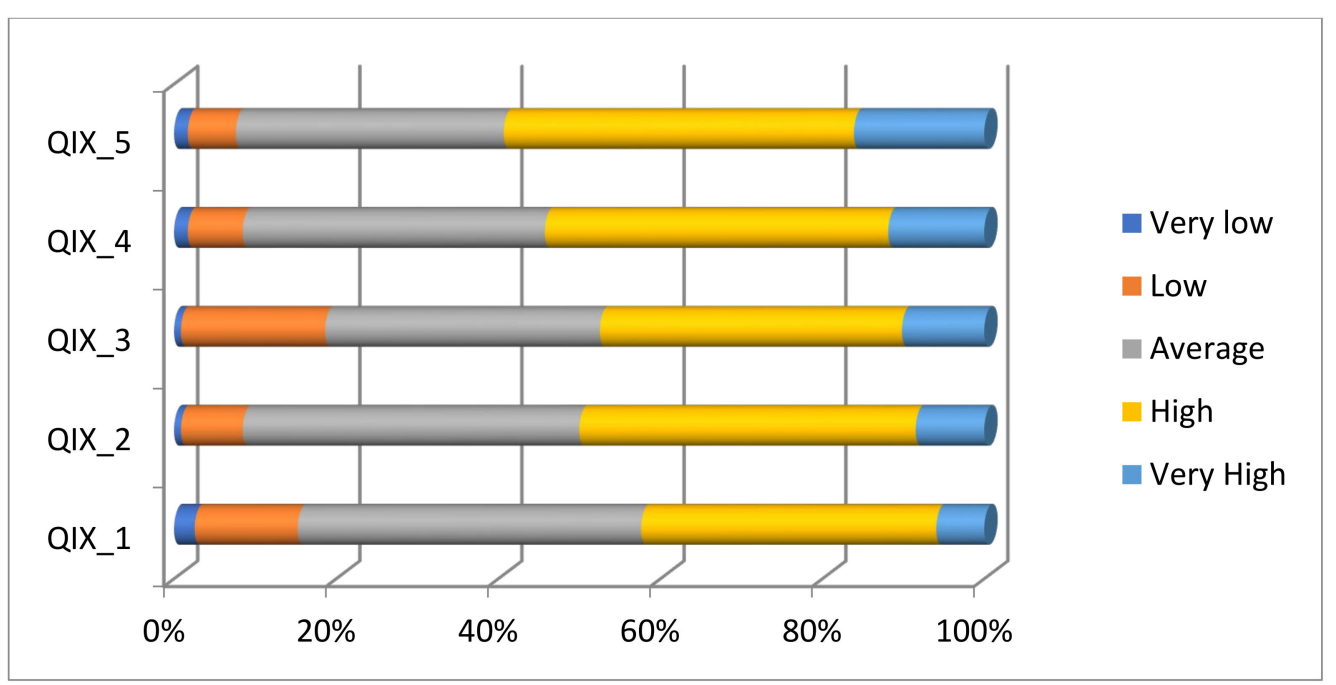

Figure 2. The distribution of responses corresponds to QOL. (Source: Author's calculation from the questionnaire survey).

\section{Structural Modeling}

\subsection{Model Building}

The dynamics surrounding the links between education, particularly NEP 2020, digitalization, and quality of life, are quite complex, and extracting information on various qualitative measures of NEP 2020 in the context of QOL is complicated and elaborative. A framework is evolved by considering the impact of NEP 2020 on QOL through a general and considerable digitalization process in terms of structural modeling. Although it is very difficult to consider extensive building blocks of NEP 2020, the key aspects pertaining to the link that we are discussing in this paper are brought out in the form of a simultaneous system of equations. The model is constructed into eight blocks each consisting of a single equation and, endogenous variables being equal to number of equations in the system, can be solved for policy analysis and other issues. More specifically, since it is cross-section data, we have avoided simulation exercises rather than concentrated on the structural relationship of the theoretical model conceived in the form of equations. The data pertaining to variables used in the model (endogenous and exogenous) have arrived from the cross-section survey of scaling. Therefore, the interpretation is critical for understanding 
structural links. For a more convenient expression of the interrelationships in the model, the specifications are formulated in double logarithmic form. Cross-section data brings forth the multicollinearity and autocorrelations in the space, and econometric consequences of the same are taken into consideration while specifying the theoretical model, and hence, we tried to avoid specification problems.

A theoretical understanding of the issues we planned to analyze here is spread around economic analysis, education, educational management, behavioral economics, sociology, and public administration, etc. Care has been taken to interlink the ideas effectively, not only for conceiving the theoretical underpinning but also for the creation of a proper simultaneous equation model which is consistent with both the theory under consideration and econometric formalities. It is important to mention here that the model was subjected to the identification issues, and both rank and order conditions were applied, and it is found that the model is neither over-identified nor under-identified. The theoretical issue of the model is pitched around experimental learning, applied knowledge, digitalization, and multidisciplinary approach and, we have tried to analyze their outcome on various aspects of QOL. The eight equations specified take care of such a link while considering various aspects of NEP 2020 into both endogenous and exogenous variables. Equation (1) is specified to capture the experimental learning and applied knowledge (ELAK), and this is explained by the important variables such as quality education and complex diversities (QECD), integration of knowledge, skill and employment (IKSE), online courses, and a financial burden (OCFB), and video and online aids for demonstration (VC). The joint determination can be the narrative of how ELAK is influenced by the dynamic process of integration of quality education, skill, and employment-oriented applied knowledge, which is more dominated by video and online demonstration aids. Probably, $\varepsilon_{1}$ could capture some of the dimensions which are not extracted in terms of proper measurements. The stochastic error terms in the structural model $\varepsilon_{2}$ to $\varepsilon_{8}$ explain pure random variation after specification bias is taken care of. Equation (2) explains the process of IKSE and the same is explained in terms of QECD, digitalization, and efficiency of communication network (DDEC), digital libraries and creative and innovative educational methods for individual development (CIED), and constraints placed by online mode on teaching and critical thinking (TCCOM). This Equation is expected to bring out the complex dynamics in knowledge and employability, which is a major building block of NEP 2020 and its ambitious project on digitalization. The process of gaining optimal outcome in the domains of physical, mental, and emotional developments (PMED) is specified in Equation (3) by the explanatory variables of CIED, ELAK, essential learning and critical thinking (ELCT), the negative impact of frequent pedagogical changes and curriculum revamping (FPCCR), and TCCOM. This specification is important as qualitative, educational, and behavioral developments of individuals are captured, and very cautiously, the specification is selected from various alternatives models that could be explaining the data generating process.

I. Experimental learning and applied knowledge

$$
\ln \mathrm{ELAK}=\alpha_{0}+\alpha_{1} \ln \mathrm{QECD}+\alpha_{2} \operatorname{lnIKSE}+\alpha_{3} \ln \mathrm{OCFB}+\alpha_{4} \ln \mathrm{VC}+\varepsilon
$$

II. Integrations of knowledge, skill and employability

$$
\ln \mathrm{IKSE}=\beta_{0}+\beta_{1} \ln \mathrm{QECD}+\beta_{2} \ln \mathrm{DDEC}+\beta_{3} \operatorname{lnCIED}+\beta_{4} \ln \mathrm{TCCOM}+\varepsilon_{2}
$$

III. Optimal outcome in the domains of physical, mental and emotional developments

$$
\begin{gathered}
\ln \mathrm{PMED}=\mu_{0}+\mu_{1} \operatorname{lnCIED}+\mu_{2} \ln \mathrm{ELCT}+\mu_{3} \ln \mathrm{ELAK}+\mu_{4} \operatorname{lnFPCCR} \\
+\mu_{5} \ln \mathrm{TCCOM}+\varepsilon_{3}
\end{gathered}
$$

IV. Videos and online aids on the creation of knowledge

$$
\ln \mathrm{VC}=\lambda_{0}+\lambda_{1} \ln \mathrm{DDEC}+\lambda_{2} \ln \mathrm{TCCOM}+\lambda_{3} \ln \mathrm{QQME}+\lambda_{4} \ln \mathrm{ELAK}+\varepsilon_{4}
$$


V. Computerized education system and online program on inclusive education

$$
\ln \mathrm{OEIE}=\eta_{0}+\eta_{1} \ln \mathrm{VC}+\eta_{2} \operatorname{lnDDEC}+\eta_{3} \ln \mathrm{OCFB}+\eta_{4} \ln \mathrm{IRDO}+\varepsilon_{5}
$$

VI. Composite quality of life

$$
\begin{aligned}
\text { In CQOL }= & \delta_{0}+\delta_{1} \operatorname{lnCIED}+\delta_{2} \ln \mathrm{ELAK}+\delta_{3} \ln \mathrm{IKSE}+\delta_{4} \ln \mathrm{PMED} \\
& +\delta_{5} \ln \mathrm{SDIR}+\delta_{6} \ln \mathrm{TCCOM}+\delta_{7} \ln \mathrm{VC}+\varepsilon_{6}
\end{aligned}
$$

VII. Social development and quality of life

$$
\ln \mathrm{SQOL}=\gamma_{0}+\gamma_{1} \operatorname{lnCIED}+\gamma_{2} \ln \mathrm{PMED}+\gamma_{3} \ln \mathrm{SDIR}+\varepsilon_{7}
$$

VIII. Income and quality of life

$$
\begin{gathered}
\ln \mathrm{YQOL}=\pi_{0}+\delta_{1} \operatorname{lnCIED}+\pi_{2} \ln \mathrm{ELAK}+\pi_{3} \ln \mathrm{IKSE} \\
+\pi_{4} \ln \mathrm{PMED}+\pi_{5} \ln \mathrm{VC}+\varepsilon_{8}
\end{gathered}
$$

Video and online aids for the knowledge gaining process are conceptualized by influencing factors such as DDEC, TCCOM, and quality versus quantity as the framework of educational attainment for both individual and social development (QQME), and ELAK. It is strongly believed that the dissemination and imparting of knowledge by digitalization essentially depend on the efficiency of online aids and this will have larger implications of the very quality of knowledge. Equation (5) considers the digitalization system on inclusive education in terms of how the computerized education system (OEIE) would work, particularly in the online mode. As per the structure, we have stressed, OEIE is influenced by VC, DDEC, OCFB, and initiatives for reducing dropouts (IRDO). All these five equations that we have formulated here collectively form a major interlinking mechanism for theoretical and econometric framework while examining QOL.

Quality of life as a target variable is addressed into three dimensions after considering various aspects of structural equations specified from Equations (1)-(5). The more important composite aspects of the QOL are assessed by using principal component analysis and amalgamating the variables such as real income; moral, ethical, and social practices; and digitalization and functioning of democratic institutions on QOL. This composite variable (CQOL) is arrived at as a weighted average by employing variances of principal components as their weight. CQOL is expected to be influenced by CIED, ELAK, IKSE, PMED, TCCOM, VC, and social and democratic instabilities and rigidities (SDIR). This elaborative model captures the complex expected outcome of composite QOL. As our survey is indicative of expectational values for variables, like the inflation expectation survey, the formation of questions that we have given to respondents exemplifies the expectational ideas on QOL. Social development and QOL, as a case of special attention, presumably propose the underlying theoretical constructs that QOL is largely influenced by socio-economic development. The dynamic changes in social development are slow and gradual, given the mass interaction of individuals, to affect social well-being and development. And accordingly, Equation (7) is formulated. Social development and QOL (SQOL) depend on CIED, PMED, and SDIR.

Finally, the very important representation of QOL is on real income. Accordingly, the questionnaire was framed to express the ability of the individuals to foresee the chances of increasing real income through the implementation of NEP 2020. If it happens so, implicitly it means that QOL moves forward as economic well-being shifts upward. This process is captured through explanatory variables such as CIED, ELAK, IKSE, and PMED. The $\alpha_{i}{ }^{\prime} s(i=0, \ldots, 4), \beta_{i}{ }^{\prime} s(i=0, \ldots, 4), \mu_{i}{ }^{\prime} s(i=0, \ldots, 5), \lambda_{i}{ }^{\prime} s(i=0, \ldots, 4), \eta_{i}{ }^{\prime} s(i=0, \ldots, 4)$, $\delta_{i}^{\prime}$ s $(i=0, \ldots, 7), \gamma_{i}^{\prime} s(i=0, \ldots, 3), \pi_{i}^{\prime}$ s $(i=0, \ldots, 5)$ are the path coefficients associated with the exogenous variables of the particular model. They are usually estimated using a maximum likelihood fit function iteratively by minimizing the differences between observed and implied covariances [36]. We used AMOS software to obtain those estimates. 
It is very important to mention that the data and information about simultaneous equation systems essentially have come from scaling techniques. Ideally, this means that we have been given clear quantitative expression to both quantitative and qualitative variables as the data collection is carried out through a questionnaire. We have carefully examined the process of articulating the variables that are essential and conditional for structural equation modeling in the context of implications of NEP 2020, digitalization, and QOL. As far as the structural relationships are concerned, it is expected that most of the coefficients will have a positive sign except $\alpha_{1}$ in the Equation (1), $\mu_{1}$ in Equation (3), $\lambda_{2}$ in Equation (4), and $\delta_{5}$ in Equation (6). The parameters used in the structural specifications generally indicate the relationship between the independent variable and the endogenous variable, including that of policy variables. The coefficients estimated for parameters give the dimensions of the relationships depending upon the sign and size of the estimated value. The underlying theory focused on investigation properly frames this relationship and hence the structural model is nothing but theoretical analysis focused on the empirical work.

\subsection{The Estimated Structural Equations}

Ideas that are propelled by the extensive seminal works of the economists namely Gary Becker and Theodore Schultz on human capital, have not been fully reflected on our structural model. The reason behind this is that the focus is on QOL, which can emerge through digitalization and NEP 2020. Physiological and social facets are considered by various explanatory variables that we have included in the above models. This resulted in the simultaneous determination of certain variables and endogeneity of dependent variables in explaining the impact of NEP 2020 on QOL. This indicates some simultaneous equation biases. A careful strategy is evolved to estimate the coefficients efficiently and to ensure the proper goodness of fit. Accordingly, we have selected a two-stage least square method for estimation. All these equations are estimated by this method and some of these equations were found to be influenced by heteroscedasticity, which may compromise the efficiency. To tackle this issue, we have calculated the t-statistics by robust standard error through White's techniques. The complete estimation of the system is given below. An interpretation of the coefficients is somewhat difficult and not straightforward in the case of estimating them through scaling techniques. The estimation of the equations is carried out in natural logarithmic form and the values would straightaway give elasticities of concerned coefficients. Since it indicates percentage changes in the concerned variables, the estimated coefficients can be interpreted meaningfully, and therefore, natural logarithmic specifications of the econometric model are used. The only caution that one might merit in explaining the one-percentage change in the independent variables as given in the methodology is that the direction of change must be taken into consideration. The process must be analyzed before arriving at a tentative idea of percentage change in the endogenous variable due to a one-percent change in the explanatory variable. Throughout the analysis of understanding the estimated model, we presumably placed these general perspectives on scale variables for percentage changes on cross-sectional studies.

The estimated Equation for Experimental Learning and Applied Knowledge seems to be very good in terms of $\mathrm{R}^{2}$ and F-statistics. All the variables are significant except QECD, and VC exerts a negative influence on ELAK with -0.65 as the coefficient value. From the opinions of the respondents, $\mathrm{VC}$ is conducive for experimental and applied knowledge. Similarly, IKSE positively contributes to the experimental and applied knowledge with an elasticity coefficient as large as 1.5. This has an enormous implication for policy analysis, and it is perceived that integration of knowledge and skill could push experimental learning and applied knowledge for greater employment opportunities. The D.W. value shows that there is no autocorrelation in space. In fact, the estimated D.W. statistics suggest that there is no stronger autocorrelation in the space across all of the equations. 
I. Experimental learning and applied knowledge

$$
\begin{aligned}
& \ln E L A K=21.56-0.07 \ln Q E C D+1.49 \ln I K S E+0.38 \ln \mathrm{OCFB}-0.65 \ln \mathrm{CC} \\
& \begin{array}{llll}
(3.89) \quad(0.65) \quad(2.21) \quad(4.60) \quad(2.34)
\end{array} \\
& R^{2}=0.56 \quad F=5.73 \quad \text { D.W. }=1.94
\end{aligned}
$$

II. Integrations of knowledge, skill and employability

$$
\begin{aligned}
& \operatorname{lnIKSE}=11.95-0.41 \ln Q E C D+0.03 \ln \mathrm{DDEC}+1.05 \operatorname{lnCIED}-0.62 \ln \mathrm{TCCOM} \\
& \begin{array}{lllll}
(7.65) & (1.83) \quad(3.55) \quad(2.26) \quad(1.95)
\end{array} \\
& \mathrm{R}^{2}=0.62 \quad \mathrm{~F}=9.31 \quad \text { D.W. }=1.87
\end{aligned}
$$

III. Optimal outcome in the domains of physical, mental and emotional developments

$$
\begin{aligned}
& \ln P M E D=-0.86-0.94 \operatorname{lnCIED}+1.42 \operatorname{lnELCT}+0.05 \operatorname{lnELAK} \\
& \text { (5.32) (1.81) (3.56) (2.98) } \\
& -0.85 \ln F P C C R-0.07 \ln T C C O M \\
& \mathrm{R}^{2}=0.43 \quad \mathrm{~F}=4.31 \quad \text { D.W. }=2.17
\end{aligned}
$$

IV. Videos and online aids on creation of knowledge

$$
\begin{aligned}
& \ln V C=2.58+0.84 \ln \text { DDEC }-0.221 \text { InTCCOM }-0.04 \ln \text { QQME + 1.14ln ELAK } \\
& \begin{array}{lllll}
(0.69) \quad(2.24) \quad(0.97) \quad(0.28) \quad(5.83)
\end{array} \\
& \mathrm{R}^{2}=0.68 \quad \mathrm{~F}=13.82 \quad \text { D.W. }=2.03
\end{aligned}
$$

V. Computerized education system and online program on inclusive education

$$
\begin{aligned}
& \ln \mathrm{OEIE}=2.87+0.51 \ln \mathrm{VC}+1.86 \operatorname{lnDDEC}+0.26 \ln \mathrm{OCFB}+0.45 \ln \mathrm{IRDO} \\
& \begin{array}{llll}
(0.33) \quad(1.99) \quad(2.68) \quad(4.18) \quad(3.06)
\end{array} \\
& \mathrm{R}^{2}=0.38 \quad \mathrm{~F}=4.31 \quad \text { D.W. }=1.85
\end{aligned}
$$

VI. Composite quality of life

$$
\begin{aligned}
& \ln C Q O L=0.55+1.04 \operatorname{lnCIED}+0.72 \ln E L A K+0.08 \operatorname{lnIKSE}+0.05 \ln P M E D \\
& \begin{array}{llll}
(1.76) \quad(2.60) & (2.77) \quad(0.730) \quad(3.04)
\end{array} \\
& -0.45 \operatorname{lnSDIR}+0.06 \operatorname{lnTCCOM}+0.43 \operatorname{lnVC} \\
& \text { (3.56) (1.05) (2.67) } \\
& \mathrm{R}^{2}=0.72 \quad \mathrm{~F}=8.52 \quad \text { D.W. }=1.76
\end{aligned}
$$

VII. Social quality of life

$$
\begin{aligned}
& \operatorname{lnSQOL}=1.58+0.25 \operatorname{lnCIED}+0.81 \ln \text { PMED }+1.45 \operatorname{lnSDIR}
\end{aligned}
$$

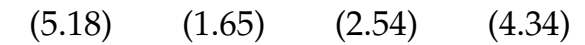

$$
\begin{aligned}
& \mathrm{R}^{2}=0.43 \quad \mathrm{~F}=3.52 \quad \text { D.W. }=2.55
\end{aligned}
$$

VIII. Income and quality of life

$$
\begin{aligned}
& \ln Y Q O L=6.82+0.77 \operatorname{lnCIED}+0.34 \operatorname{lnELAK}+0.04 \operatorname{lnIKSE}+0.32 \ln P M E D \\
& \begin{array}{llll}
(9.55) \quad(3.42) \quad(1.95) \quad(3.66) \quad(2.67)
\end{array} \\
& +0.67 \ln \mathrm{VC} \\
& \text { (2.77) } \\
& \begin{array}{lll}
\mathrm{R}^{2}=0.52 & \mathrm{~F}=6.52 & \text { D.W. }=2.01
\end{array}
\end{aligned}
$$

Equation (10) is estimated to be excellent. The coefficient of CIED influences very strongly the integration process of knowledge, skill, and employability. Digital libraries and innovative educational methods and compromising quality education produce a negative 
impact on IKSE. Therefore, NEP 2020 needs to address the social reality of diversity, educational exclusion and allow all in realistic perspectives. An optimal outcome in the domains of physical, mental, and emotional development seems to have moderate fit. These results are obtained despite a good amount of analytical disposition of model formation and data mining process. Surprisingly, CIED and FPCCR give rise to a very significant and largely negative impact on PMED. NEP 2020 must cautiously consider the creation of innovative educational methods and digital libraries as against the counterproductive impact of frequent changes in pedagogy and curriculum. Adding to this, TCCOM also has a negative impact on PMED though the size of the coefficient is very small. Equation (12) pertaining to videos and online aids on the knowledge gaining process throws a meaningful light that TCCOM and QQME have brought out the negative impact on VC and while the size and magnitude of coefficients related to ELAK and DDCE more than compensate for the negative impact of TCCOM and QQME. Dependent variable OEIE in Equation (13) sounds satisfactory in terms of $t$-values, and all the coefficients of explanatory variables are positive as expected and show exceptional values of elasticities for most of the variables. This indicates computerized education systems and online programs can generate a massive scale of inclusive education.

Equations (14)-(16) exclusively concentrate on the estimates of various dimensions of QOL. The composite QOL variable, as explained above, turns out to be having an extraordinary goodness-of-fit of 0.72 because the data used for analysis is a cross-section. Moreover, most of the variables are significant and have a positive sign as expected. IKSC, which stands for the integration of knowledge, skill, and employment, though the coefficient is positive, is insignificant. All other variables immensely contribute to the changes in the composite QOL. SDIR, not only significant but also produces a negative impact on QOL. This seems to be a caution for evolving policy. Equation (15) is compact and estimated to be good. Probably it suffers from a mild autocorrelation from space as D. $\mathrm{W}$ statistics is 2.55 . All explanatory variables explain the variation in dependent variables such as CIED, PMED, and SDIR for improving QOL at a society level. This confesses the truth of the importance of these three variables for the implications of NEP 2020 on QOL. The last Equation (16), which is a key indicator of QOL expressed in terms of real income, the dependent variable of the Equation, turned out to be excellent in terms of all statistical measures such as t-values, $\mathrm{R}^{2}$, and F-statistics. Incidentally, it does not suffer from autocorrelation. Key variables such as CIED, ELAK, VC, and PMED produce a long-lasting, substantial positive impact on QOL based on income.

Apart from our empirical observations, it is contextually important to quote the dynamic views from newspaper articles, discussion papers, and government documents on follow-ups pertaining to the NEP 2020. Various issues of The Economic Times and the followup actions by the education ministry observed that the multidisciplinary approach to the learning and digitalization can go a long way in attracting foreign students and rejuvenating the very quality of the educational system in India, which can pay way to integrate and unite knowledge gaining process across countries and regions. The government of India is very seriously taking up the mission of systematically implementing NEP 2020. However, one might feel that there is some sluggishness based purely on the progress and intensity of COVID-19. The Times of India's 20 December 2021 edition narrates the observations made by the government, "the new provisions of the NEP 2020 in the form of multiple entry and exit option is something to be cherished as this academic flexibility will have a positive impact on the students as regards availing of different career opportunities at different times depending upon their intrinsic learning and inherent attitude. Technological interventions in t education are a boon for the students of the generation and emphasize that the teachers should also be able to keep up with the student who is moving ahead too fast owning to the accessibility of information, avenues, means and talent. Equally important is the education of teachers, parents, and elders as the challenges not only optimum education but also to prevent dis-education". 
When we articulate sustainable education, it is imperative to have a curriculum based on strategic plans, global coverage, and locally relevant issues included in the pedagogy for preparing young minds for progressive nation-building [37-39]. We hope that the new education policy will become a sophisticated document for achieving the stated goals of quality of education, QOL, and provide students with the essential competencies to adapt to future sustainability challenges.

\section{Limitations}

NEP 2020 is a vast policy measure and implementation is going to be a complex issue. Given the framework of this attempt, in our opinion, there are limitations. NEP 2020 addresses exhaustively various educational policy reforms, and guidelines. We have endeavored ourselves into the critical few features in attempting to explain QOL. This investigation is a cross-section analysis based on the questionnaire survey method and one can venture into panel data modeling by using the difference in differences method by taking two surveys from the same respondents. Total implementation at all levels requires proper time and a substantial number of financial resources from the government. Such a viability of social cost-benefit analysis and sources of finance are not adequately addressed. The scope is vast in the future to build a time series model and presently, it is not possible due to the reason that the implementation of NEP 2020 started only last year. The impact of certain economic factors influencing QOL has not been explicitly considered in building a simultaneous equation model.

\section{Conclusion and Policy Recommendations}

This inquiry into phenomena of QOL getting influenced by NEP 2020 addresses uniquely in terms of cross-section analysis and we claim that it is not exhaustive. QOL and education are the variables that are difficult to precisely measure in quantitative terms and hence, the implications and inferences are carefully analyzed on the range of issues that are selected for structural modeling. The deduction of, last but not least, the analytical findings can be interpreted within the framework considered in the simultaneous equation analysis. By going with our estimates, it seems that though NEP 2020 is a popular and mandated educational policy for educational reforms toward a better future, the expected implementation of the policy would be very difficult in the context of digitalization and QOL.

Social and cultural rigidities coupled with educational disparities and income inequalities will present massive bottlenecks for achieving the desired outcome. Incidentally, both the recovery of the economy and foster economic growth enables some aspects like reducing poverty and unemployment, as visualized by trickle-down theory, and eventually, depth of inequalities can be partly taken care of. One of the most stunning aspects of NEP 2020 is multidisciplinary and lifelong learning. In our opinion, remarkable progress on the quality of life can be made possible with flexibility in proper life-long education and training, which can combine skill, experience, quality of education, and rigidity of the segmented labor market into better opportunities and employment. The multidisciplinary approach is a novel concept that can give exorbitant social dividends provided institutional constraints such as curriculum building and quality teaching, proper conduct of multidisciplinary quality research at university levels are properly addressed in line with the policy aims of NEP 2020. The policy looks attractive on paper, but there are huge difficulties in implementing when it comes to improving the QOL.

ELAK, PMED, VC, and CQOL are mutually explained and pedagogical changes and experimental learning CIED, IKSE have a stronger bearing on QOL as they can be observed from the estimates of structural parameters. According to our hypothesis skill development, employability, and multidimensional human development promote QOL. This can be substantiated from the estimates of the Equations (14)-(16). The government's agenda on digitalization multidisciplinary approach, lifelong learning strengthen QOL. These extracts from our hypotheses can be is proved from the estimates of Equations (9), (10), (14), and (16). 
Among various factors that influence QOL, as per our estimates, real income continues to be the dominant one. Digitalization, experimental learning, flexibility and life-long learning, quality education, and integration of knowledge with skill and employment strongly explain the variations in the QOL. This implies economic and social investment in all these educational variables will improve the QOL considerably. It is also evident that digitalization will play a significant role not only in inclusive education and development but also in reinforcing the positive elements of QOL. Notwithstanding, considering all of the lacunas and constraints in implementing NEP 2020, the fruits of the outcomes will be advantages both for individuals and society in strengthening social well-being, the standard of living, and growth and prosperity.

From the viewpoint of policymakers and democratic representatives, our study and estimates throw some meaningful observations for improving QOL via new education policy. As digitalization, experimental learning, and the integration of knowledge, skill, and employability enormously promotes QOL, the choice for the representatives should be to strengthen institutional governance in promoting digitalization, skill formation, and synergizing multidisciplinary approach with employability and opportunities. Although the study has not gone into deeper details of examining issues on public finance, particularly on expenditure on implementing NEP 2020, it is evident that some normative tradeoffs should be made when considering the appropriate choices to optimize desired objectives. State and central finances are somewhat flexible in recognizing the implementation of NEP 2020, and will impact the long-lasting and durable choices that will be made to make NEP 2020 a reality in the coming years.

Author Contributions: Conceptualization, K.M.; Introduction, K.S.; Methodology, K.M. and K.S.; Questionnaire, K.M.; Explorative Data Analysis, K.M.; Structural Equation model, K.S.; Formal Analysis, K.M., K.S. and Y.K.; Conclusions and policy recommendation, K.M., K.S. and Y.K. All authors have read and agreed to the published version of the manuscript.

Funding: This research was done by Peter the Great St. Petersburg Polytechnic University and supported under the strategic academic leadership program 'Priority 2030' of the Russian Federation (Agreement 075-15-2021-1333 dated 30 September 2021).

Institutional Review Board Statement: Not applicable.

Informed Consent Statement: Not applicable.

Data Availability Statement: Not applicable.

Acknowledgments: Authors are thankful for useful comments from the anonymous referees and the editorial board for improving the manuscripts. However, the usual disclaimer applies. We are deeply indebted to Yury Klochkov of Peter the Great St. Petersburg Polytechnic University, St. Petersburg, Russian Federation, for taking care of the finances for the publication.

Conflicts of Interest: The authors declare no conflict of interest.

\section{Appendix A. Questionnaires}

QV. According to the New Structure of School Education Do You Think that (1-Strongly

Disagree, 2-Disagree, 3-Neutral,

4-Agree, 5-Strongly Agree)

\begin{tabular}{ll}
\hline Code & \multicolumn{1}{c}{ Description } \\
\hline QV_1 & $\begin{array}{l}\text { As envisaged by the global education agenda (SDG-4) and subsequently by NEP 2020, it } \\
\text { is possible to attain optimal outcomes in the domains of physical, mental, and emotional } \\
\text { development. }\end{array}$ \\
\hline QV_2 & $\begin{array}{l}\text { The professionally qualified educators and continuous assessment could create a strong } \\
\text { foundation for early childhood development and quality education for a future } \\
\text { paradigm shift in the quality of life. }\end{array}$ \\
\hline
\end{tabular}




\begin{tabular}{ll}
\hline QV_3 & $\begin{array}{l}\text { The technology-assisted educational system through enjoyable and inspirational books } \\
\text { would create an enormous impact on the value system of individuals. }\end{array}$ \\
\hline QV_4 & $\begin{array}{l}\text { Digital libraries are the future realities and source of considerable information and } \\
\text { knowledge for the creative and innovative educational development of individuals. }\end{array}$ \\
\hline QV_5 & $\begin{array}{l}\text { The overall initiatives and comprehensive approach will be undertaken to reduce } \\
\text { drop-out rates drastically. }\end{array}$ \\
\hline QV_6 & $\begin{array}{l}\text { Reduced curriculum content to enhance essential learning and critical thinking leads to } \\
\text { the holistic development of the individual. }\end{array}$ \\
\hline QV_7 & \begin{tabular}{l} 
Experimental learning, flexibility, and multilingualism promote applied knowledge. \\
\hline QV_8
\end{tabular} $\begin{array}{l}\text { Pedagogical and Curriculum structure would bring fundamental quality change in the } \\
\text { educational development of both individuals and society. }\end{array}$ \\
\hline
\end{tabular}

QVI. What Do You Think about Achieving Equitable Access to the Highest Quality

Education for All by 2040? (1-Strongly

Disagree, 2-Disagree, 3-Neutral, 4-Agree, 5-Strongly Agree)

\begin{tabular}{ll} 
Code & \multicolumn{1}{c}{ Description } \\
\hline QVI_1 & Possible to achieve as the stated period is very long. \\
\hline QVI_2 & Not possible as gender, social, educational, and economic inequalities are pervasive. \\
\hline QVI_3 & Partially possible if the government seriously implements the conceived NEP 2020. \\
\hline QVI_4 & $\begin{array}{l}\text { The educational outcome cannot be expected as conceived since there are social and } \\
\text { democratic instabilities and rigidities. }\end{array}$ \\
\hline
\end{tabular}

QVII. Do You Think that the Foundation for Higher Education in NEP 2020 Has the

Following Important Ingredients for

Developing a Standard of Living and Quality of Life? (1-Strongly Disagree, 2-Disagree, 3-Neutral, 4-Agree, 5-Strongly Agree)

\begin{tabular}{|c|c|}
\hline Code & Description \\
\hline QVII_1 & $\begin{array}{l}\text { The multidisciplinary approach towards the learning and knowledge gaining process is } \\
\text { a fundamental and new paradigm shift of the new NEP } 2020 \text { in delivering high-quality } \\
\text { higher education. }\end{array}$ \\
\hline QVII_2 & $\begin{array}{l}\text { Institutional autonomy, quality teachers, and appropriate leadership provide enormous } \\
\text { background for quality education in the context of complex diversities. }\end{array}$ \\
\hline QVII_3 & $\begin{array}{l}\text { Proper revamping of curriculum and promoting genuinely quality research induce } \\
\text { speedy innovation suitable for local needs. }\end{array}$ \\
\hline QVII_4 & $\begin{array}{l}\text { Autonomy, individual freedom, and a conducive atmosphere for learning are not fully } \\
\text { addressed by NEP } 2020 .\end{array}$ \\
\hline QVII_5 & $\begin{array}{l}\text { A multidisciplinary approach can be misleading in the context of super specialization } \\
\text { and specialized innovations. }\end{array}$ \\
\hline QVII_6 & Frequent pedagogical changes and curriculum revamping could be counterproductive. \\
\hline QVII_7 & $\begin{array}{l}\text { Flexibility and innovation in learning could be produced only in the choice-based credit } \\
\text { system. }\end{array}$ \\
\hline QVII_8 & $\begin{array}{l}\text { Resources of the Higher learning institutions including finance are not optimally } \\
\text { utilized. }\end{array}$ \\
\hline QVII_9 & $\begin{array}{l}\text { Introducing the traditional method of Indian learning into the modern educational } \\
\text { system cannot produce the required learning outcomes. }\end{array}$ \\
\hline QVII_10 & $\begin{array}{l}\text { Access to higher education to all and more inclusive quality higher education are } \\
\text { mutually exclusive. }\end{array}$ \\
\hline QVII_11 & $\begin{array}{l}\text { The government's plan on vocational education can integrate knowledge, skill, and } \\
\text { employability quickly. }\end{array}$ \\
\hline
\end{tabular}


QVIII. According to NEP 2020, the Following Issues Are such that (1-Strongly Disagree,

2-Disagree, 3-Neutral, 4-Agree,

5-Strongly Agree)

\begin{tabular}{ll}
\hline Code & \multicolumn{1}{c}{ Description } \\
\hline QVIII_1 & $\begin{array}{l}\text { The mass online program and computerized network education system are going to } \\
\text { take care of inclusive education. }\end{array}$ \\
\hline QVIII2 & $\begin{array}{l}\text { Online education for regular courses puts financial burden on both providers and } \\
\text { users and also on the government. }\end{array}$ \\
\hline QVIII_3 & $\begin{array}{l}\text { Teaching and critical thinking in the process of learning are going to be compromised } \\
\text { in the online mode. }\end{array}$ \\
\hline QVII_4 & $\begin{array}{l}\text { Educational videos, animations, and picture content are going to be the new mantra of } \\
\text { teaching and learning. }\end{array}$ \\
\hline QVIII_5 & $\begin{array}{l}\text { Videos and online demonstration boards are going to be revitalizing various } \\
\text { dimensions of the creation and dissemination of knowledge. }\end{array}$ \\
\hline QVIII66 & $\begin{array}{l}\text { Democratization of education and digitalization depends on the efficacy and efficiency } \\
\text { of the communication network. }\end{array}$ \\
\hline QVIII_7 & $\begin{array}{l}\text { Individuals are subjected to multiple interpretations and misinformation on the } \\
\text { digitalization of education. }\end{array}$ \\
\hline QVIII_8 & $\begin{array}{l}\text { Digitalization can never replace conventional teaching and learning process. } \\
\text { QVIII_9 }\end{array} \begin{array}{l}\text { Digitalization of knowledge can be speedy across various social groups and may } \\
\text { promote a mass group of learning and sharing of information and knowledge. }\end{array}$ \\
\hline QVIII_10 & $\begin{array}{l}\text { Digitalization can provide mass education without compromising the quality at } \\
\text { minimal cost and time. }\end{array}$ \\
\hline
\end{tabular}

QIX. Based on the above Questions Answered by You, Kindly Provide an Appropriate Answer to the Following the Issues

Related to Quality of Life Ranging from the Scale of 1-5 (1-Very Low, 2-Low, 3-Average, 4-High, 5-Very High)

\begin{tabular}{ll}
\hline Code & \multicolumn{1}{c}{ Description } \\
\hline QIX_1 & $\begin{array}{l}\text { After formally going through education based on NEP } 2020 \text { your chance of increasing } \\
\text { real income is fairly }\end{array}$ \\
\hline QIX_2 & $\begin{array}{l}\text { Net consequences of NEP } 2020 \text { on individual's ethical, moral, and social practices in } \\
\text { day-to-day life will be __ }\end{array}$ \\
\hline QIX_3 & $\begin{array}{l}\text { Overall social dynamics in terms of reduction in the social conflict, an amalgamation of } \\
\text { social interest, and social development will be __ }\end{array}$ \\
\hline QIX_4 & $\begin{array}{l}\text { NEP } 2020 \text { would enable, individuals who effectively participate in the digitalized } \\
\text { democratic process, to provide appropriate social development and proper functioning } \\
\text { to be _ }\end{array}$ \\
QIX_5 $\begin{array}{l}\text { NEP 2020 would enable, individuals who effectively participate in the digitalized } \\
\text { democratic process, to provide appropriate social development and proper functioning } \\
\text { of democratic institutions more transparently and equitably. This outcome is expected } \\
\text { to be _ }\end{array}$
\end{tabular}




\section{References}

1. NEP 2020. National Education Policy 2020; Ministry of Human Resource Development, Government of India: New Delhi, India, 2020.

2. UNHDP. United Nations Human Development Report; Oxford University Press Inc: Oxford, UK, 2003.

3. Edgerton, D.; Roberts, L.W.; von Below, S. Education and Quality of Life. In Handbook of Social Indicators and Quality of Life Research; Springer: Berlin/Heidelberg, Germany, 2012. [CrossRef]

4. $\quad$ Rapley, M. Quality of Life Research: A Critical Introduction; Sage: Thousand Oaks, CA, USA, 2003.

5. Phillips, D. Qualityof Life: Concept, Policy, and Practice; Routledge: New York, NY, USA, 2006.

6. Cummins, R.A. The domains of life satisfaction: An attempt to order chaos. Soc. Indic. Res. 1996, 38, 303-328. [CrossRef]

7. Kerckhoff, A.C. Transitionfrom School to Work in Comparative Perspective. In Handbook of the Sociology of Education; Hallinan, M.T., Ed.; Kluwer Academic/Plenum Publishers: New York, NY, USA, 2000; pp. 453-474.

8. Kerckhoff, A.C. Education and social stratification processes in comparative perspective. Sociol. Educ. 2001, 78, 3-18. [CrossRef]

9. Ferris, A.L. The uses of social indicators. Soc. Forces 1988, 66, 601-617. [CrossRef]

10. Land, K.C. Social Indicators. In Encyclopedia of Sociology; Borgatta, E.F., Montgomery, R., Eds.; Macmillan Reference: New York, NY, USA, 2000; pp. 2682-2690.

11. Lonescu, D.D.; Lonescu, A.M.; Jaba, E. The Investments in Education and Quality of Life. J. Knowl. Manag. Econ. Inf. Technol. 2013, 3,70 .

12. OECD. Education at a Glance 2011: OECD Indicators; OECD Publishing: Paris, France, 2011.

13. Ngelu, J.M.; Omwenga, J.; Mungatu, J.; Iravo, M. Effect of Free Basic Education on Improving Quality of Life in Kenya: Evidence from Machakos County. Dev. Ctry. Stud. 2017, 7, 54-62.

14. Winters, J.V. Human Capital, Higher Education Institutions, and Quality of Life. Reg. Sci. Urban Econ. 2011, 41, 446-454. [CrossRef]

15. Lazic, Z.; Đordevic, A.; Gazizulina, A. Improvement of Quality of Higher Education Institutions as a Basis for Improvement of Quality of Life. Sustainability 2021, 13, 4149. [CrossRef]

16. Kryzhanovskij, O.A.; Baburina, N.A.; Ljovkina, A.O. How to Make Digitalization Better Serve an Increasing Quality of Life? Sustainability 2021, 13, 611. [CrossRef]

17. Ali, M.A.; Alam, K.; Rafiq, S. Does digital inclusion affect quality of life? Evidence from Australian household panel data. Telemat. Informat. 2020, 51, 101405. [CrossRef]

18. Atkinson, R.D.; Castro, D.D. Public Policy Principles for Driving Digital Quality of Life. In Digital Quality of Life: Understanding the Personal and Social Benefits of the Information Technology Revolution; Information Technology and Innovation Foundation: Washington, DC, USA, 2008; Chapter 3.

19. Correa, D.K. Education and Training. In Digital Quality of Life: Understanding the Personal and Social Benefits of the Information Technology Revolution; Information Technology and Innovation Foundation: Washington, DC, USA, 2008; Chapter 4.

20. Maaravi, Y.; Heller, B. Digital Innovation in Times of Crisis: How Mashups Improve Quality ofEducation. Sustainability 2021, 13, 7082. [CrossRef]

21. Stefanovic, S.; Klochkova, E. Digitalization of Teaching and Learning as a Tool for Increasing Students' Satisfaction and Educational Efficiency: Using Smart Platforms in EFL. Sustainability 2021, 13, 4892. [CrossRef]

22. Đordevic, A.; Klochkov, Y.; Arsovski, S.; Stefanovic, N.; Shamina, L.; Pavlovic, A. The Impact of ICT Support and the EFQM Criteria on Sustainable Business Excellence in Higher Education Institutions. Sustainability 2021, 13, 7523. [CrossRef]

23. Bunduchi, R.; Weisshaar, C.; Smart, A.U. Mapping the benefits and costs associated with process innovation: The case of RFID, adoption. Technovation 2011, 31, 505-521. [CrossRef]

24. Lee, S.M.; Trimi, S. Convergence innovation in the digital age and in the COVID-19 pandemic crisis. J. Bus. Res. 2020, 123, 14-22. [CrossRef] [PubMed]

25. UNESCO. Education for Sustainable Development Toolkit. Learning and Training Tools No. 1. 2006. Available online: https:/ / unesdoc.unesco.org/images/0015/001524/152453eo.pdf (accessed on 30 October 2021).

26. UNESCO. Education for Sustainable Development in action. Learning and Training Tools No. 4. 2012. Available online: https:/ / sustainabledevelopment.un.org/content/documents/926unesco9.pdf (accessed on 30 October 2021).

27. Muralidharan, K. Sustainable Development and Quality of Life: Through Lean, Green and Clean Concepts; Springer Nature: Singapore, 2021.

28. Womack, J.P.; Jones, D.T.; Roos, D. The Machine That Changed the World: The Story of Lean Production; Rawson Associates: New York, NY, USA, 1990.

29. Gryna, F.M.; Chua, R.C.H.; Defeo, J. Juran's Quality Planning and Analysis for Enterprise Quality; Tata McGraw-Hill: New Delhi, India, 2007.

30. Rampersad, H.K.; El-Homsi, A. TPS-Lean Six Sigma; SARA Books, Private Limited: New Delhi, India, 2008.

31. Li, Y.; Terenteva, D.; Konnikova, O.; Konnikov, E. Comparative Assessment of Sustainable Consumption Based on the Digital Information Environment Content-Thematic Component Differentiation. Sustainability 2021, 13, 7215. [CrossRef]

32. Shanmugan, K.; Sharma, D. Multidisciplinary Approach to Sustainable Development Goals: Some Issues and Reflections; Amazon Kindle Publishing company: Seattle, WA, USA, 2021. 
33. Frisch, M.B. Evidence-Based Well-Being/Positive Psychology Assessment and Intervention with Quality-of-Life Therapy and Coaching and the Quality-of-Life Inventory (QOLI). Soc. Indic. Res. 2013, 114, 193-227. [CrossRef]

34. Manstead, A. The wellbeing effect of education. Evid. Brief. 2014, 34, 1-2.

35. Mahajan, K.K.; Saxena, M.K.; Ali, Q.M.; Mahajan, R.K. National Education Policy: Reflections from Stakeholders; White Falcon Publishers: New Delhi, India, 2020.

36. India Indicators, Trading Economics, Janurary. 2022. Available online: https://tradingeconomics.com (accessed on 4 January 2022).

37. Objective of Nep to Correct Past Anomalies: Union Minister, Pti. 20 December 2021. Available online: https:/ / economictimes. indiatimes.com (accessed on 4 January 2022).

38. Bunting, G.; Davidson, J.; Osborn, P. Sustainability Skills Survey, Staff Questionnaire; University of Wales: Cardiff, UK, 2012.

39. Hoover, E.; Burford, G. Curriculum Audit Full Report: Sustainability/Sustainable Development; University of Brighton: Brighton, UK, 2013. 